\title{
A COMPARISON BETWEEN EMPIRICAL PROCEDURES FOR THE DEFINITION OF VULNERABILITY CLASSES OF MASONRY BUILDINGS: APPLICATION TO FIVE HISTORICAL CENTRES STRUCK BY 2016 CENTRAL ITALY EARTHQUAKE
}

\author{
YLENIA SARETTA $^{1 *}$, LUCA SBROGIÓ ${ }^{1}$ AND MARIA R. VALLUZZI ${ }^{1}$ \\ ${ }^{1}$ Department of Cultural Heritage (dBC) \\ Università degli Studi di Padova \\ Piazza Capitaniato 7, 35139 Padova, Italy \\ e-mail: ylenia.saretta@unipd.it (*corresponding author), luca.sbrogio@phd.unipd.it, \\ mariarosa.valluzzi@unipd.it
}

Keywords: Masonry, Vulnerability Classes, Damage Analysis, Strengthened Interventions

\begin{abstract}
The definition of seismic risk scenarios necessarily depends on the attribution of a vulnerability class to each building of a stock. In the macroseismic scale (EMS-98) the vulnerability class - from A to $F$ - results from the combination between horizontal and vertical structures. On the basis of post-event surveys carried out in Italy after the earthquakes occurred in the last 50 years, many rules for converting the masonry quality and the stiffness of horizontal diaphragms into a vulnerability class have been proposed. However, despite the now high number of retrofitted or strengthened buildings in Italy, structural interventions are not mentioned in these procedures, except for metal tie rods and r.c. tie beams.

The paper proposes a critical approach to the definition of vulnerability classes, by the means of applying the conversion rules to the same sample of 525 masonry buildings located in five historical centres struck by 2016 Central Italy earthquake: Acquasanta Terme, Campi Alto di Norcia, Castelsantangelo sul Nera, Muccia and Vezzano. They have been chosen due to the extensive strengthening campaigns that had been carried out after earlier seismic events. The preliminary recognition of the structural features of each building happens at the terms of the MUSE-DV Masonry, a rapid visual screening procedure recently proposed by the authors.

The damage probability matrices (DPMs), obtained from each conversion, are compared to those from a theoretical model proposed for the EMS-98. Given the same poor masonry quality, the existing rules classify buildings in class A or B depending only on floors' stiffness and horizontal connections. As a result, both low and high damage may appear in the same vulnerability class causing a bimodal trend in the damage distributions. Conversely, the MUSE-DV procedure allows to reduce these two frequency peaks by considering interventions. In fact, overall interventions, even on very poor masonry structures, may lead to a very low damage and, consequently, to low vulnerability classes (even $C$ or D), while uncontrolled interventions could obtain a high damage and a high vulnerability. The twofold consequence is that a) structural interventions have a 'relative', i.e. positive or negative, contribution; $b$ ) the usual limitation to $A$ and $B$ vulnerability classes for random masonry buildings needs to be widened to better explain the damage observed in the 2016 Central Italy earthquake.
\end{abstract}




\section{INTRODUCTION}

A vulnerability class is an essential factor in the definition of damage scenarios at urban scale and, consequently, in the calibration of prevention strategies and vulnerability models for the reduction of seismic risk. Such class, which is an empirical evaluation of a building's aptitude to suffer a certain damage grade, is rapidly attributed through the observation of a building's structural features. The European Macroseismic Scale (EMS-98, [1]) proposes six classes, from A to F, at decreasing vulnerability; the scale identifies a most likely vulnerability class and a range of probable behaviour for each structural type. Typically, masonry buildings may belong to classes A, B and C; D is only referred to seismically designed buildings. Classes $\mathrm{D}, \mathrm{E}$ and $\mathrm{F}$ are attributed to r.c. or steel structures.

However, the earlier macroseismic scales (MCS, [2]; MSK-76 [3]) were limited to just three classes (i.e. A, B and C), related both to masonry and r.c. structures, which may be compared to the first three EMS-98 classes [4].

Damage Probability Matrices (DPMs), which define the observed or expected damage grade (from 0, negligible damage, to 5, collapse, according to EMS-98) depending on vulnerability class and macroseismic intensity, are widely used to sum up empirical damage analysis. Theoretical DPMs have been derived from those implicitly described in the EMS-98 by [5] and, in this paper, are compared to those obtained from the empirical sample.

The paper deals with a critical approach in the definition of vulnerability classes starting from the observation of structural elements, by the means of applying some of the rules

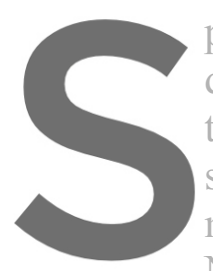
proposed in the scientific literature ( $\$ 1.1$.
data coming from surveys begun after th
the empirical DPMs for a sample of 52
struck by the Central Italy earthquake
macroseismic intensity [6]: Acquasanta
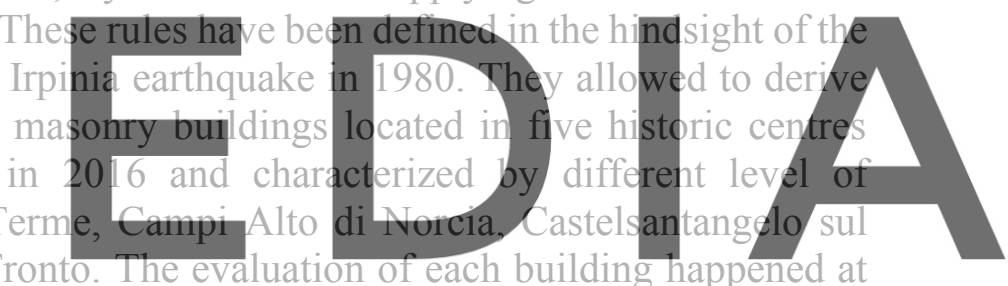

Nera, Muccia e Vezzano di Arquata del Tronto. The evaluation of each building happened at the terms of the MUSE-DV. Masonry (MUltilivel assessment of. SEismic Damage and

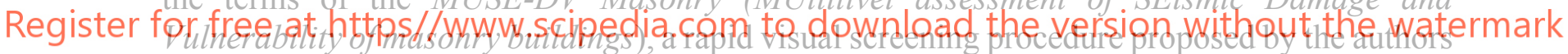

to evaluate the specific structural features of the buildings in the involved area (\$1.2). The resuits are compared both to the theoretical model $(\$ 2.2)$ and to the real observed behaviour $(\S 3)$, in order to underline the contribution of strengthening interventions on buildings.

\subsection{Literature procedures for the attribution of the vulnerability class}

The seismicity of Italy is remarkable [7]. Most effort of researchers aims at developing and improving rapid visual screening procedures to estimate seismic damage and vulnerability [8]. The amount of data collected in the last 50 years represents an inestimable scientific heritage for prevention purposes [9]. DPMs have been used in Italy since 1980 (Irpinia earthquake) referring to MSK-76 scale [10]. This scale has been commonly employed also for later empirical elaborations. In that occasion, the data collection happened by the means of a standardized rapid visual screening (RVS) procedure called GNDT I level [11], whose heir is the AeDES RVS, the present standard procedure to define a building's usability and damage grade [12]. In both procedures, the combination of masonry quality and horizontal structures' stiffness yields the estimated vulnerability class of a building.

In the GNDT I level RVS, surveyors are asked to recognize the vertical structures among 
eleven categories, according to masonry units and their texture, and the horizontal ones among nine categories, according to the bearing elements' material and the presence of connections to the walls. Aiming at defining the vulnerability classes from the mutual combination of vertical and horizontal elements, [13] developed a conversion rule based on GNDT I level RVS, while [14] simplified the vertical types distinguishing only among bad, medium, and good quality. [15] used a more descriptive approach referring to field stone as a bad quality, hewn stone as a medium quality and bricks as the good one.

Table 1: Comparison among different interpretations of conversion of Section 3 of AeDES RVS according to MSK-76. Grey background highlights different attribution of vulnerability class

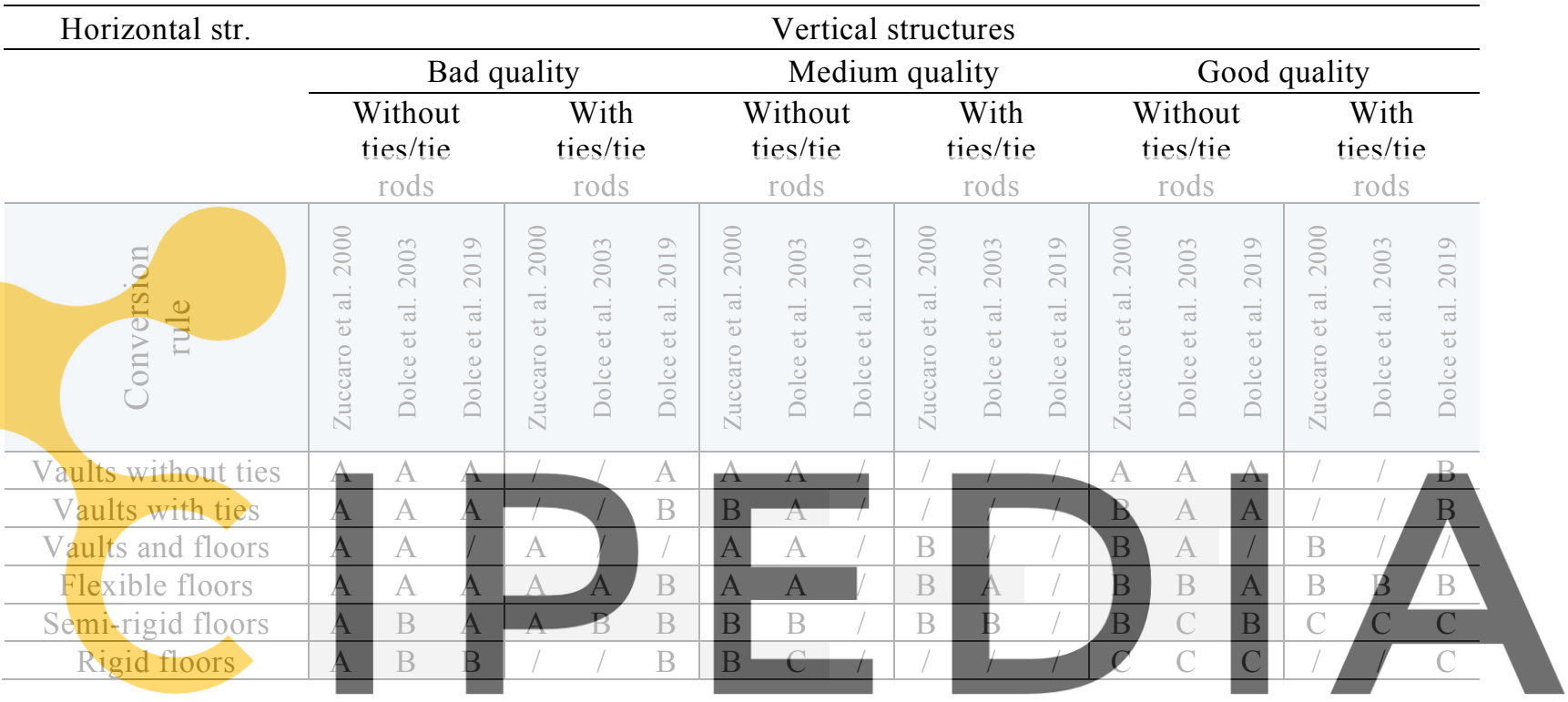

For masonry buildings, the AeDES RVS requires i) to distinguish only between random

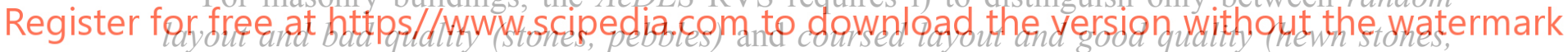

bricks), ii) to define the presence of tie rods and/or tie beams and iii) to recognize vaults and floors' stiffness (flexible, semirigid or rigid fioors). Comparing to the previous RV S procedure, this empirical evaluation represents an important simplification in the surveyors' work. At the beginning [14,15], surveyors were asked to recognize masonry features (units, texture, and layout) and floors elements in a very detailed way; conversely, in [9]'s opinion surveyors should have a different role, in which they may be identified as "evaluators" instead of "observers". That is why in the AeDES RVS they are asked to identify masonry's good or bad behaviour and floors' capability to redistribute seismic loads rather than their structural features.

Strengthening interventions may be characterized but they are not included in any of the procedures for the identification of the vulnerability classes [16].

After the L'Aquila earthquake (2009), [17] proposed another rule, while [9] widened it starting from a complete review of post-earthquake data collected since 1980 . In this case, D class identifies seismically resistant dwellings built after 1974 (first seismic Italian code).

Table 1 proposes a comparison among three different procedures $[9,13,14]$ to determine the vulnerability class. For the sake of comparability, the eleven vertical structures in [13] are grouped in bad, medium, or good quality, although they were all used for the identification of 
the class. [13] propose the only procedure which considers the differences between masonry block structures (tuff, full bricks, lightweight hollow bricks, no load-bearing lightweight hollow bricks used as load-bearing structure, concrete blocks).

As one may observe in Table 1, in the behavioural approach by [9], medium quality masonry is not included, while the presence of tie rods or tie beams definitely improves a building's estimated seismic response (from class A to B), regardless of its masonry quality. The presence of rigid floors leads to class C. The comparison between [13] and [14] highlights that the latter proposes less vulnerable classes, excepted for vaults.

\section{THE ATTRIBUTION OF THE VULNERABILITY CLASSES TO ORDINARY BUILDINGS IN FIVE HISTORICAL CENTRES STRUCK BY 2016 CENTRAL ITALY EARTHQUAKE}

\subsection{The case studies}

Starting from August 24 $4^{\text {th }}, 2016,140$ municipalities located in Central Italy had been struck by a strong seismic swarm $[18,19]$. Devastating effects on civil and monumental heritage have been observed, especially on buildings located near the epicentres or where site effects exist [20]. Poor quality of masonry structures caused the crumbling of the stones rather than the activation of rigid macro-blocks and the identification of damage mechanisms. As matter of a fact, Central Italy dwellings' masonries are characterized by uncoursed or brought to courses rubble or hewn stones

'relative' effects, i.e. por an earthquake hit the

Horizontal timber

ribbed slabs with tie bea

$21,22]$. If vertical
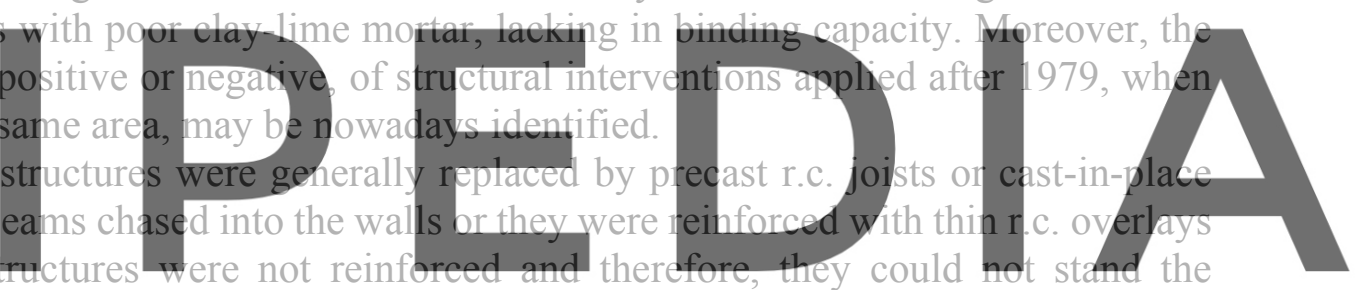

increase of seismic loads, partial interventions are obtained. Conversely, holistic interventions

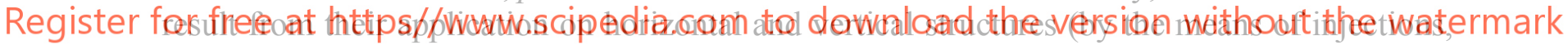

r.c. jacketing, deep repointing of mortar, internal bricks wythes) and on the mutual connection, ensuring a favourable effect and, thus, decreasing the damage grade [19,23].

The recognition of the type and the effectiveness of the structural interventions of each building happened at the terms of the MUSE-DV Masonry RVS, a rapid visual screening procedure recently developed by the authors [8]. The RVS procedure is divided into four sections; sections 0, 1 and 2 evaluate a building's seismic damage and vulnerability, with increasing level of accuracy. Finally, section 3 analyses masonry quality, horizontal and roofing structures and strengthening interventions.

In this paper, the application of the RVS to 525 masonry buildings located in five case studies is presented. In order to define the damage grade and the structural features of each building, Section 0 (Building identification, overall vulnerability and damage) and Section 3 (Building features) were compiled. The application of the conversion rules to this sample of masonry buildings allowed to define the vulnerability classes.

Five historical centres have been chosen according to different macroseismic intensities [6] and, hence, damage situations (Table 2): they are Acquasanta Terme (ACQ) and Vezzano di Arquata del Tronto (VZZ) in the district of Ascoli Piceno, Campi Alto di Norcia (CMP) in the district of Perugia, Castelsantangelo sul Nera (CSN) and Muccia (MCC) in the district of 
Macerata. They are characterized by quite homogeneous structural features; a more detailed analysis about buildings' seismic behaviour, historical and structural features is developed in $[19,23]$. According to empirical damage grades, CSN suffered the most severe damage (mean value $=3,08$, using [24]). A medium level of mean damage was registered in VZZ $(2,24)$ and in CMP $(2,39)$, even though $37 \%$ of buildings suffered of low damage thanks to favourable structural interventions applied after past seismic events. No collapses were recognized in MCC and in ACQ, where a relatively low mean damage was registered, respectively of 1,51 and 0,98.

Table 2: Distance from epicentre (Oct 30, 2016), EMS-98 intensities registred by [6], total number of analyzed structural units, damage grades and mean damage calculated according to [24]

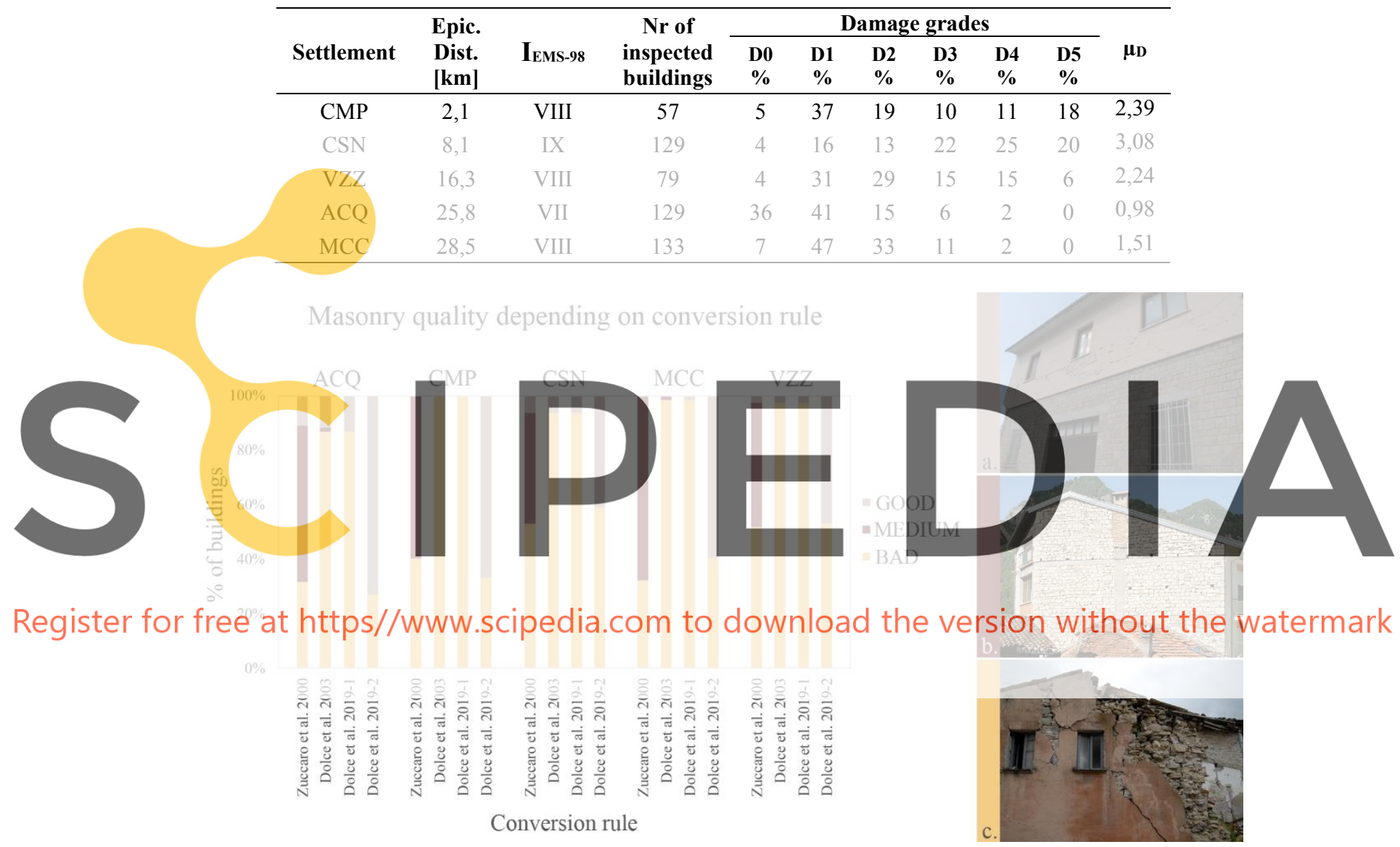

Figure 1: Masonry quality depending on conversion rule. On the right, some examples of masonry quality:

a) good, CSN; b) medium, ACQ; c) bad, CSN

\subsection{The attribution of the vulnerability classes using literature procedures}

Structural features recognized by MUSE-DV Masonry RVS were adapted to the conversion rules (Table 1) as a function of i) masonry units and mortars or the overall quality of bearing walls and ii) floors' types and stiffness.

Two approaches were followed in applying the rule proposed by [9]: i) in the first one (in the following defined as [9]-1), the mere observation of masonry texture and mortar consistency yielded random/bad quality o coursed/good quality; ii) in the second one ([9]-2), strengthening interventions' influence participated in the classification as well, changing the 
final result. In other words, in the latter case the surveyor was asked to be an evaluator more than an observer. Such information is collected by the AeDES RVS, but it is not considered in the vulnerability class definition.

Figure 1 shows masonry quality as a function of the conversion rule. In the case of compresence of different masonry textures, the worst were considered. As one may see, medium quality results only from the application of [13], characterized by more possibilities in the structural combination, at the expense of the rapidity of the whole procedure. Results from the application of [14] and [9] -1 are similar, while a more precise interpretation of a building's behaviour comes from [9]-2.

The evaluation of horizontal structures' stiffness is the same in each procedure; sometimes the floors' identification was prevented by exterior surveys only, hence roofs' stiffness becomes relevant. Semirigid diaphragms are the most recurrent (35\%), followed by flexible (32\%) and rigid ones $(25 \%)$; the remaining cases are vaults with or without tie rods (typically in CMP) and not evaluated structures (N.E.). Almost a half of the surveyed buildings (52\%) shows tie rods and tie beams, partially evaluated by [9] and [13].

The empirical DPMs of the sample were defined according to the three chosen conversion rules (Table 1) and considering also the two approaches for [9] (Figure 2). It is worth noting that class D is totally absent and only a few buildings belong to class $\mathrm{C}$ (Table 3). Class A is typical of most cases, especially with [13]'s rule, except for MCC, where the widespread rigid diaphragms cause a half of the buildings to belong to class B. According to [9]-1 rule, most buildings are classified as B, but in the case of $\mathrm{ACQ}$ the $12 \%$ of the surveyed dwellings are in class $\mathrm{C}$, thanks to a bett observe an increase of masonry's original feat Table 3: Relative d
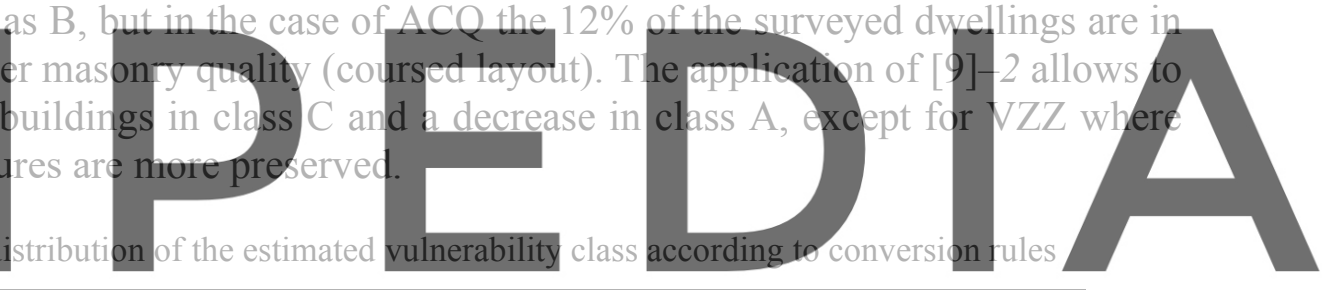

$$
\text { Zuccaro et al. Dolce et al. Dolce et al. Dolce et al. }
$$

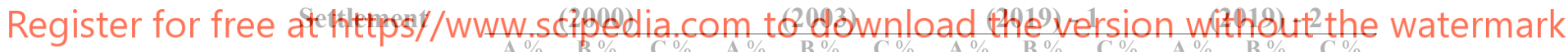

\begin{tabular}{ccccccccccccc}
\hline ACQ (I=VII) & 60 & 29 & 12 & 57 & 31 & 12 & 45 & 43 & 12 & 20 & 39 & 41 \\
\hline CMP $_{(I=V I I I)}$ & 82 & 18 & 0 & 63 & 37 & 0 & 39 & 61 & 0 & 9 & 72 & 19 \\
\hline CSN (I=IX) & 65 & 3 & 5 & 53 & 42 & 5 & 25 & 71 & 4 & 22 & 53 & 25 \\
\hline MCC (I=VIII) & 54 & 45 & 1 & 41 & 58 & 1 & 35 & 64 & 1 & 26 & 44 & 30 \\
\hline VZZ (I=VIII) $^{84}$ & 13 & 3 & 75 & 22 & 3 & 65 & 32 & 3 & 57 & 23 & 20 \\
\hline
\end{tabular}

The obtained DPMs were compared to the theoretical ones, defined starting from the EMS98 [5], with poor results. The recurring presence of peaks in low damage grades (D0 and D1) and an overlapping of damage grades for the three classes happen at low macroseismic intensity (ACQ, I=VII), differently from [5]. Similarly happens for I=VIII:

- in MCC, A and B classes overlap, D1 and D2 are the most recurrent damage grades, even though D3 and D4 should be the peaks according to [5];

- in VZZ a bimodal trend characterizes the damage grades of the two most vulnerable classes, with two frequency peaks in D2 and D4 for class A and in D1 and D3 for class $\mathrm{B}$ : as a consequence, $\mathrm{B}$ appears more vulnerable than $\mathrm{A}$ for [9]-1. One may suppose that the D2 peak for class A should describe buildings that actually belong to B or lower classes and that the D3 peak for class B could gather higher vulnerable dwellings; 
- in CMP different results come out from each procedure.

In the case of CSN (I=IX), the first two procedures seem to be comparable to the theoretical model, although low damage for class A exceeds the expected, while [9]-1's procedure provides unfavourable results which could describe a $\mathrm{I}=\mathrm{X}$ situation. More coherent results come from [9]-2's procedure, even though they cannot solve the contrast between the other procedures and the theoretical model. Therefore, the theoretical model derived from the EMS98 is not coherent with the DPMs obtained from the conversion rules, although specifically adapted to the sample. Class A sometimes appears to be less vulnerable than B or they show the same damage grades. This fact may be explained with the compresence of buildings belonging to different vulnerability classes in the same group.

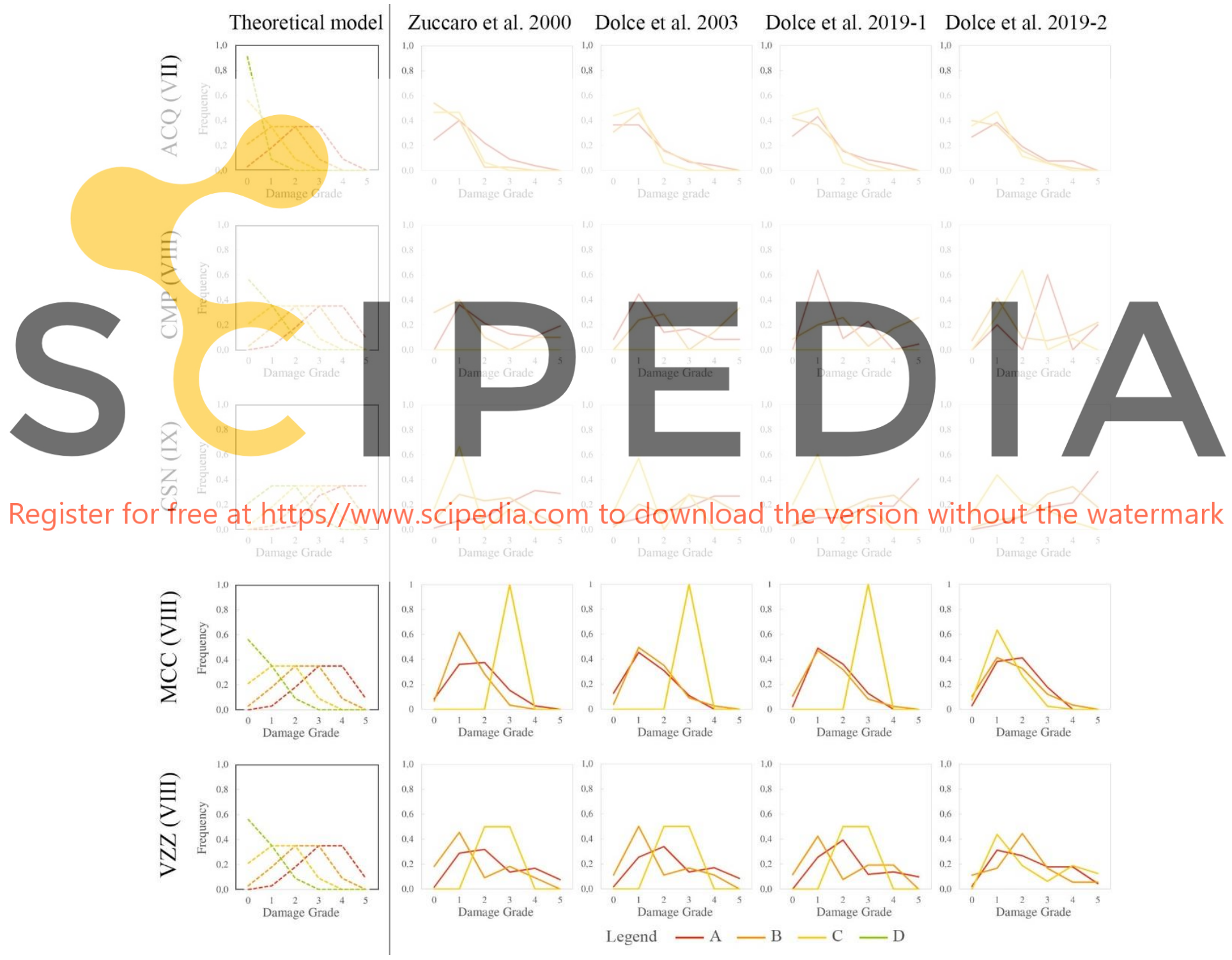

Figure 2: DPMs for surveyed centres. Application of conversion rules to the sample of buildings (from second to fifth column) and comparison with theoretical model [5] (first column, dashed lines) 


\section{SOME OBSERVATIONS IN THE HINDSIGHT OF 2016 SEISMIC SWARM: THE ROLE OF INTERVENTIONS IN BUILDINGS' SEISMIC BEHAVIOUR}

The application of the literature conversion rules to the data set (Figure 2) has highlighted their limits in the vulnerability classification. In fact, these procedures do not take into account the influence of structural strengthening interventions applied on buildings in a recent past, observing only the presence of tie rods or tie beams. The effectiveness of these connection systems on seismic behaviour is taken for granted, especially if they are associated to rigid diaphragms (cfr. Table 1 and 3). However, observations demonstrated that the effectiveness of tie rods is limited by masonry quality at the anchoring (Figure 3a, see also [25]), while r.c. curbs on weak masonries cause crumbling, overturning and sliding of the walls (Figure 3b, c) [21].

Interventions revealed a 'relative', i.e. favourable or unfavourable, contribution to a building's seismic behaviour [8,16,20,21,23]. Table 4 sums up the typical structural interventions observed in the five centres. This information cannot be ignored anymore: a great amount of strengthened buildings were recognized in CSN (85\%), MCC (94\%) and CMP (98\%). In the last case, structural interventions applied after the 1979 earthquake [26] caused a dichotomy in buildings' behaviour (see Table 2): buildings with holistic interventions suffered of minor damage, while on the other hand buildings with partial interventions (see \$2.1) caused severe damage and buildings' collapses. The miss use of this data in conversion rules does not allow to attribute the correct vulnerability class to strengthened buildings.

Moreover, according to the conversion rules, the unconditional favourable effect of rigid

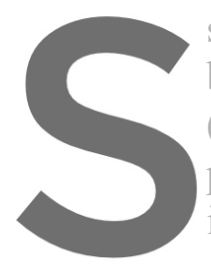
slabs on a building's seismic behaviour yields
basis of the empirical evidence, that could be
(Figure 4a), while near the epicentre rigid diap
phenomena and a building's collapse (Figu
increases, and the building is prone to suffer of 1997 Umbria-Marche earthquake [27].
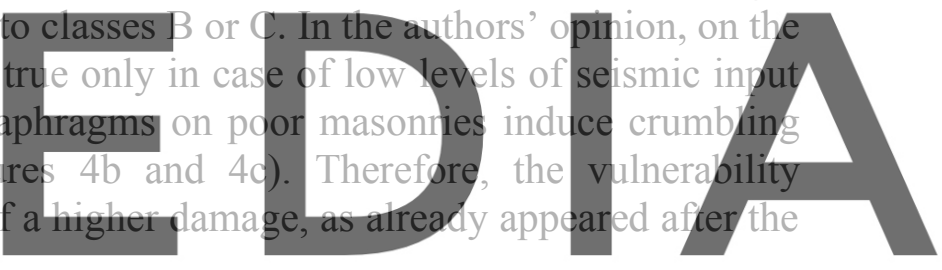

Another problem of the literature rules is the limitation to the first three classes, among which

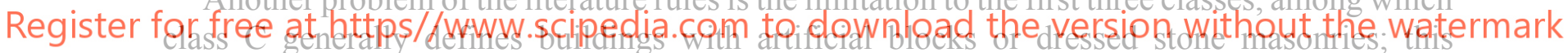

classification needs to be widened to better explain the real seismic behaviour. The issue has been recentiy discussed by the authors [21,23], underiining that buildings with holistic interventions could be actually described by class $\mathrm{D}$, typical of new buildings $(\S 1.1)$, while partial interventions yield class A. Original buildings without strengthening interventions (stone masonries and timber floors) belong to class A, such as buildings with original unreinforced stone masonries and replaced diaphragms with rigid or semirigid ones (Figure 5a). As well as recent buildings (Table 5), deep repointing and thick cementitious plasters on bearing walls allow to reach class $\mathrm{C}$ (Figure $5 \mathrm{~b}$ ), while core interventions, such as grout injections and r.c. jacketing, could lead to class D, regardless floors' stiffness (Figure 5c). Class B is not explicitly defined, but it expresses the possible range of vulnerability thanks to the structural details and the masonry quality.

Figure 6 shows the new DPMs derived from the proposed classification for the five case studies: the widened classification (from class A to D) better describes the observed buildings' seismic behaviour and the comparison with the theoretical model (Figure 2), with more coherent results. Bimodal trends have been removed, the use of class $\mathrm{D}$ and the spreading of class $\mathrm{C}$ for each centre lead to a better distribution of the six damage peaks. 

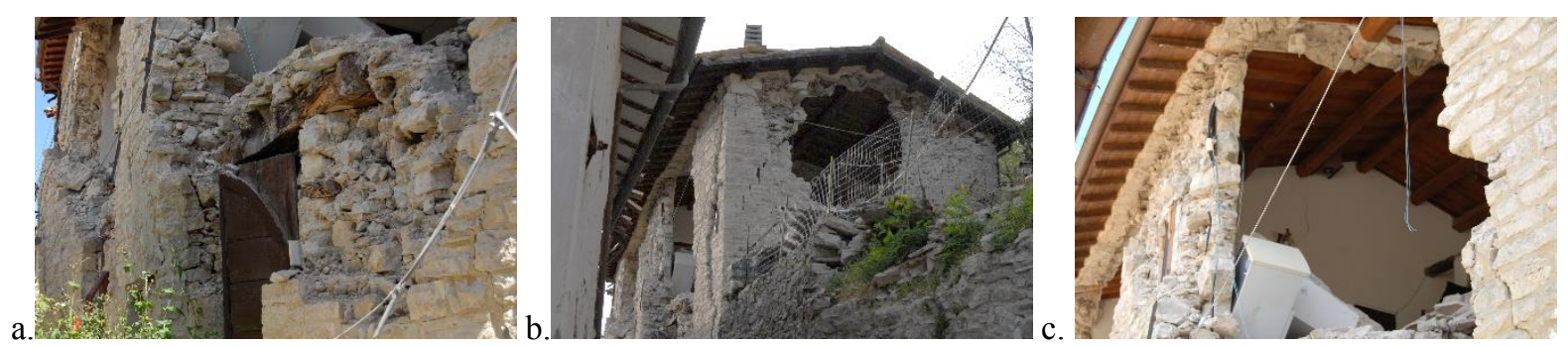

Figure 3: Examples of poor seismic behaviour in a strengthened masonry building, CSN: a) Not effective tie rods on bad quality masonry; b) overturning of last storey and c) of internal bearing walls due to r.c. curbs and to excess of stiffness and weight of reinforced timber roof
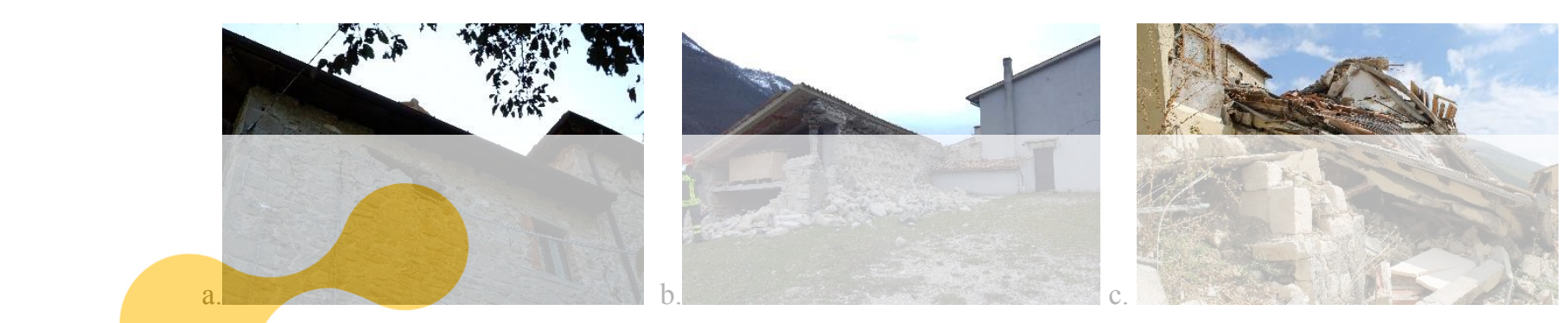

Figure 4: Examples of damage due to rigid roofs: a) Slip of the roof and horizontal arch (VZZ); b) Masonry leaves separation and local overturning (CSN); c) Total collapse due to crumbling of masonry (CMP)
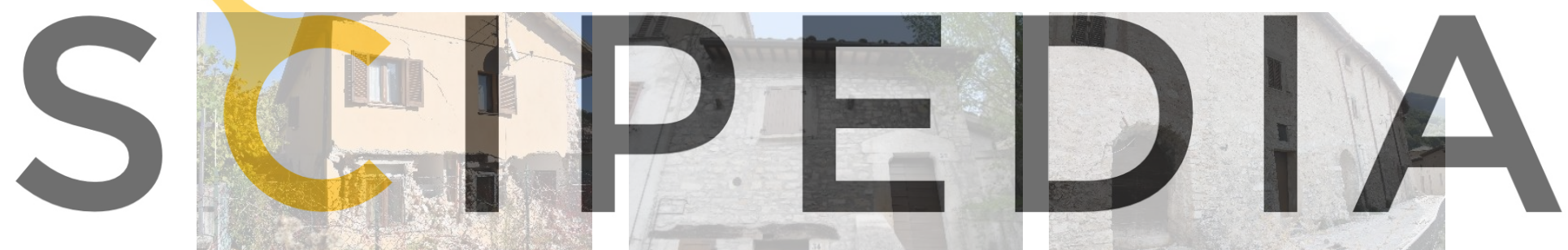

Register for free at https//www.scipedia.com to download the version without the watermark Figure 5: a) Class A building: poor masonry quality and floors replaced with rigid ones (MCC); b) C class

building: random layout limestone masonry reinforced by deep repointing with cementitious mortar (CSN); c) D

class building: random layout limestone masonry reinforced by grout injections and r.c. jacketing (internal side)

(CMP)

Table 4: Relative presence of interventions on walls and horizontal structures in the sample

\begin{tabular}{|c|c|c|c|c|c|c|c|}
\hline 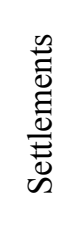 & 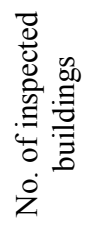 & 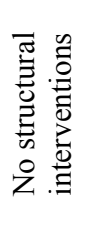 & 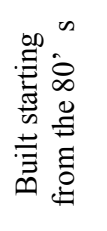 & 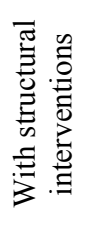 & 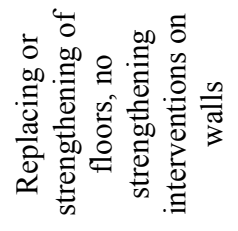 & 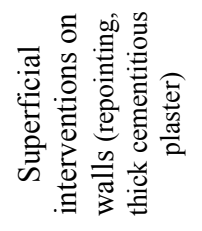 & 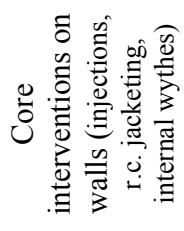 \\
\hline ACQ & 129 & $12 \%$ & $11 \%$ & $78 \%$ & $8 \%$ & $45 \%$ & $5 \%$ \\
\hline CMP & 57 & $2 \%$ & $0 \%$ & $98 \%$ & $32 \%$ & $63 \%$ & $47 \%$ \\
\hline CSN & 128 & $10 \%$ & $5 \%$ & $85 \%$ & $32 \%$ & $20 \%$ & $9 \%$ \\
\hline $\mathrm{MCC}$ & 133 & $6 \%$ & $0 \%$ & $94 \%$ & $24 \%$ & $44 \%$ & $13 \%$ \\
\hline VZZ & 79 & $18 \%$ & $1 \%$ & $81 \%$ & $10 \%$ & $20 \%$ & $5 \%$ \\
\hline
\end{tabular}


Table 5: Vulnerability class according to empirical observations of the authors

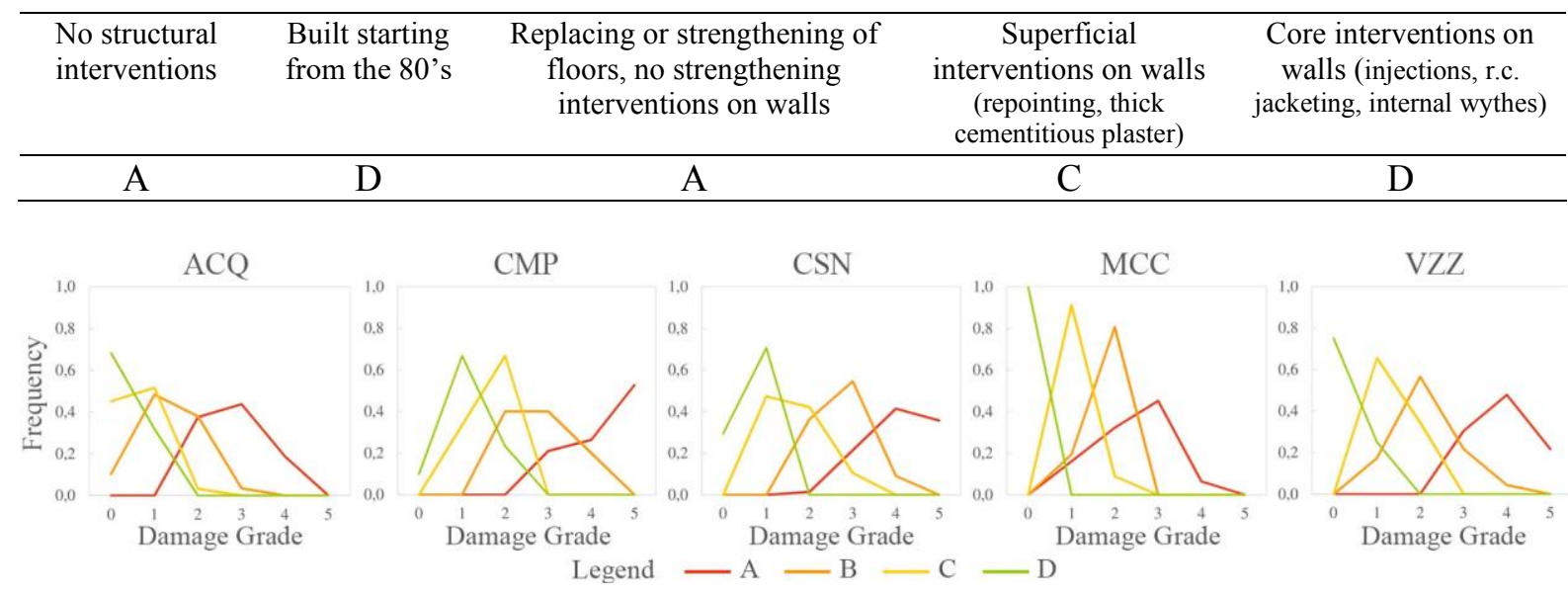

Figure 6: Empirical DPMs according to Table 5

\section{CONCLUSIONS}

The definition of a building's vulnerability class is a staple in the proposal of risk reduction strategies. Using post-earthquake survey data, some procedures have been developed in order to identify the vulnerability class considering the interaction among bearing walls, horizontal structures and connections. The application of these procedures to 525 buildings inside five centres struck by the 20 for the specific context. distributions of differen In field surveys, the effect after past seismic events are
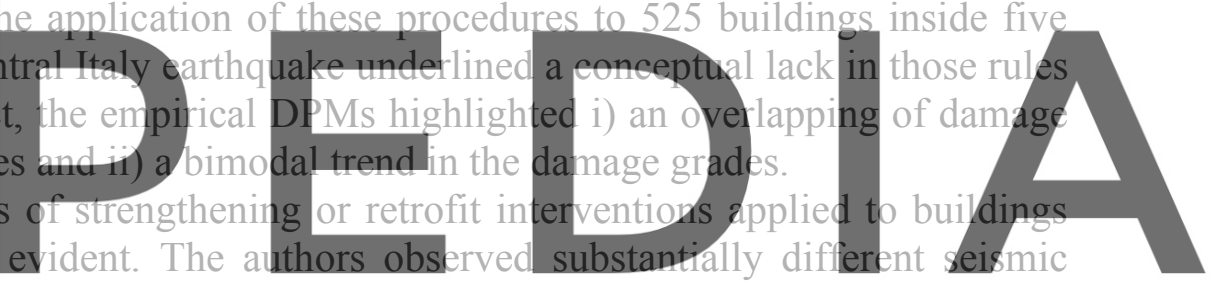

behaviours within the same centre between unreinforced and strengthened buildings, and

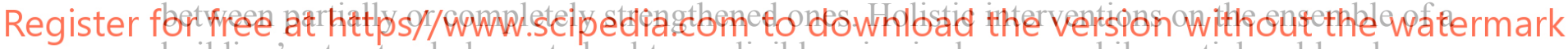
building's structural elements lead to negligible seismic damage, while partial and local ones cause severe damage. Consequently, some discrepancies between the observed damage (hence the explicated vulnerability) and the vulnerability estimate (hence the expected damage grade) through literature rules have been remarked. In particular:

i) according to those rules, rigid slabs always improve the seismic behaviour, regardless of the masonry quality; the same happens for r.c. tie beams;

ii) those rules consider only the first three vulnerability classes (A to C), but class $\mathrm{C}$ (buildings with coursed layout and good masonry quality) is uncommon in the sample, where random stone masonries prevail. Classes A or B only, defined according to the floors' stiffness, are not able to completely describe the observed buildings' behaviour;

iii) the lack in those rules of the observation of strengthening interventions cannot lead to the correct vulnerability class. Actually, flexible diaphragms replaced with rigid ones caused such severe damage phenomena (e.g. masonry crumbling) that classes B or C do not express these situations. On the other hand, holistic interventions both on vertical and horizontal structures cannot be described by classes A or B, as the random layout of stone masonries would classify them.

Trying to reduce these limitations, the authors have revised the attribution of the EMS-98 
vulnerability class to strengthened buildings $[21,23]$. As a rule:

i) unfavourable interventions allow to attribute class A, regardless of floors' stiffness;

ii) favourable interventions could lead to class $\mathrm{C}$ (superficial interventions on the walls) or D (core interventions). B is a 'possible' class, resulting from the evaluation of structural details and materials.

These statements allowed to propose more coherent DPMs if compared to the empirical observations, thanks to a wider range of vulnerability classes.

The procedure needs to be developed through the validation on other case studies and the evaluation of other parameters, in order to better describe the empirical data according to the EMS-98 model, preserving the rapidity that large scale vulnerability assessment needs.

Acknowledgements. This research is framed within the 2016-2018/2019-2021 Reluis Projects. The authors wish to thank eng. F. Molinari and eng. M. Vettore for their help during the surveys.

\section{REFERENCES}

[1] Grünthal, G. European Macroseismic Scale 1998. Cahiers du Centre Européen de Géodynamique et de Séismologie, Vol. XV, Luxembourg, (1998).

[2] Sieberg, A. Geologie der Erdbeben. Handbuch der Geophysik (1930) 2(4):552-555.

[3] Medvedev, S.V. Seismic Intensity Scale MSK-76. Publications of the Institute of Geophysics, Polish Academy of Sciences (1977) A-6(117):95-102.

[4] Molin, D. Considerazioni sull'eventuale adozione in Italia della scala macrosismica europea (EMS-1998). XXII GNGTS “Gruppo Nazionale di Geofisica della Terra Solida”, Rome, 18-20 November (2003).

[5] Bernardini, A., Giovinazzi, S., Lagomarsino, S. and Parodi, S. The vulnerability assessment of current buildings by a macroseismic approach derived from the EMS-98 scale, Asociaciòn Espanola de Ingenieria Sismica. Girona, 8-11 May (2007).

[6] Locati, M., Camassi, R., Rovida, A., Ercolani, E., Bernardini, et al. Database macrosismico italiano (DBMI15), version 2.0, INGV (2019).

[7] Rovida, A., Locati, M., Camassi, R., Lolli, B. and Gasperini, P. Catalogo Parametrico dei Terremoti Italiani (CPTI15), version 2.0, INGV (2019).

[8] Saretta, Y., Sbrogiò, L., Molinari, F., Vettore, M. and Valluzzi M.R. Proposta di un nuovo strumento multilivello per la valutazione del danno e della vulnerabilità a scala urbana: la procedura MUSE-DV Masonry per la valutazione empirica del comportamento di edifici consolidati. Progettazione sismica (2020) no.1, Quaderno 1.

[9] Dolce, M., Speranza, E., Giordano, F., Borzi, B., Bocchi, F., et al. Observed damage database of past Italian earthquakes: the Da.D.O. WebGIS. Bollettino di Geofisica Teorica ed Applicata (2019) 60(2):141-164.

[10] Braga, F., Dolce, M. and Liberatore, D. A statistical study on damaged buildings and an ensuing review of the MSK-76 scale. Proceedings of the 7th ECEE, Athens (1982).

[11] Gruppo Nazionale per la Difesa dai Terremoti \& Consiglio Nazionale delle Ricerche. Scheda di esposizione e vulnerabilità di primo livello e di rilevamento danni, GNDT (1994).

[12] Baggio, C., Bernardini, A., Colozza, R., Corazza, L., Della Bella, M. et al. Manuale per la compilazione della scheda di $1^{\circ}$ livello di rilevamento danno, pronto intervento $e$ agibilità per edifici ordinari nell'emergenza post-sismica (AeDES). PCM-DPC, (2014).

[13] Zuccaro, G., Papa, F. and Baratta, A. Aggiornamento delle mappe a scala nazionale di 
vulnerabilità sismica delle strutture edilizie. In: Bernardini A. (Ed.): La vulnerabilità degli edifici: valutazione a scala nazionale della vulnerabilità sismica degli edifici ordinari. Roma, CNR-GNDT, (2000), pp. 133-166.

[14] Dolce, M., Masi, A., Marino, M. and Vona, M. Earthquake damage scenarios of the building stock of Potenza (Southern Italy) including site effects. Bull. Earthquake Engineering (2003) 1(1):115-140.

[15] Di Pasquale G., Orsini G. and Romeo R.W. New Developments in Seismic Risk Assessment in Italy. Bull. Earthquake Engineering (2005) 3(1):101-128.

[16] Sisti, R., Di Ludovico, M., Borri, A. and Prota, A. Damage assessment and the effectiveness of prevention: the response of ordinary unreinforced masonry buildings in Norcia during the Central Italy 2016-2017 seismic sequence. Bull. Earthquake Engineering (2019) 17:5609-5629.

[17] Dolce M. and Goretti A. Building damage assessment after the 2009 Abruzzi earthquake. Bull. Earthquake Engineering (2015) 13(8):2241-2264.

[18] Valensise, G., Tarabusi, G., Guidoboni, E. and Ferrari, G. The forgotten vulnerability: A geology-and history-based approach for ranking the seismic risk of earthquake-prone communities of the Italian Apennines. Int. J. Disaster Risk Reduction (2017) 25:289-300.

[19] Valluzzi, M.R., Sbrogiò, L., Saretta, Y. and Wenliuhan, H. Seismic response of masonry buildings in historical centres struck by the 2016 Central Italy earthquake. Part 1-feature recognition and damage evaluation. International Journal of Architectural Heritage (n.d.) Submitted.

[20] Fiorentino, G., Forte, A., Pagano, E., Sabetta, F., Baggio, C., et al. Damage patterns in the town of Amatrice after August 24th 2016 Central Italy earthquakes. Bull. Earthquake Engineering (2018) 16:1399-1423.

[21] Vettore, M., Saretta, Y., Sbrogiò, L. and Valluzzi, M.R. (2020). A New Methodology for the Survey and Evaluation of Seismic Damage and Vulnerability Entailed by Structural Interventions on Masonry Buildings: Validation on the Town of Castelsantangelo sul Nera (MC), Italy. Int. J. Architectural Heritage (2020) Published Online.

[22] Gavarini, C. (ed.) Costruzioni e terremoto. Roma, Nisa, (1983).

[23] Sbrogiò, L., Saretta, Y. and Valluzzi, M.R. Seismic response of masonry buildings in historical centres struck by the 2016 Central Italy earthquake. Part 2-calibration of a vulnerability model for strengthened conditions. Construction and Building Materials (n.d.) Submitted.

[24] Giovinazzi, S. The vulnerability assessment and the damage scenario in seismic risk analysis. PhD Thesis, University Carolo-Wilhelmina and University of Florence, (2005).

[25] D'Ayala, D. F. and Paganoni, S. Assessment and analysis of damage in L'Aquila historic city centre after 6th April 2009. Bull. Earthquake Engineering (2011) 9(1):81-104.

[26] Sbrogiò, L., Valluzzi, M. R. and Cardani G. Recenti sviluppi sulle previsioni di vulnerabilità sismica di Campi Alto di Norcia alla luce degli interventi di riparazione e/o consolidamento e del sisma Centro Italia 2016, XVIII Congresso Nazionale ANIDIS "L'ingegneria Sismica in Italia”, Ascoli Piceno, 15-19 settembre (2019).

[27] Borri, A. and De Maria, A. Alcune considerazioni in materia di analisi e di interventi sugli edifici in muratura in zona sismica. XI Convegno Nazionale ANIDIS "L'ingegneria sismica in Italia”, Genova, 25-29 gennaio (2004). 